\title{
Genomic and neoantigen evolution from primary tumor to first metastases in head and neck squamous cell carcinoma
}

\author{
Charles R. Schutt ${ }^{1, *}$, Hua Sun ${ }^{1,2, *}$, Jaya Sarin Pradhan ${ }^{3}$, Yvonne Saenger $^{4}$, Jessica \\ Ley $^{1}$, Douglas Adkins ${ }^{1,7}$, Matthew Ingham ${ }^{4}$, Li Ding ${ }^{1,2,5,7}$ and Brian A. Van Tine ${ }^{1,6,7}$ \\ ${ }^{1}$ Division of Medical Oncology, Washington University in St. Louis, St. Louis, MO, USA \\ ${ }^{2}$ McDonnell Genome Institute, Washington University in St. Louis, St. Louis, MO, USA \\ ${ }^{3}$ Department of Pathology and Cell Biology, Columbia University, New York, NY, USA \\ ${ }^{4}$ Division of Hematology/Oncology, Columbia University, New York, NY, USA \\ ${ }^{5}$ Department of Genetics, Washington University in St. Louis, St. Louis, MO, USA \\ ${ }^{6}$ Division of Pediatric Hematology and Oncology, St. Louis Children's Hospital, St. Louis, MO, USA \\ ${ }^{7}$ Siteman Cancer Center, St. Louis, MO, USA \\ *Co-first authors
}

Correspondence to: Brian A. Van Tine, email: bvantine@wustl.edu

Keywords: head and neck squamous cell carcinoma; neoantigens; mutational evolution; tumor relapse; immune cell infiltration Abbreviations: ECM: Extracellular Matrix; HNSCC: Head and neck cell squamous-cell carcinomas; HPV: human papilloma virus; IHC: immunohistochemistry; WES: whole exome sequencing

Received: February 02, $2021 \quad$ Accepted: February 15, $2021 \quad$ Published: March 16, 2021

Copyright: $\odot 2021$ Schutt et al. This is an open access article distributed under the terms of the Creative Commons Attribution License (CC BY 3.0), which permits unrestricted use, distribution, and reproduction in any medium, provided the original author and source are credited.

\section{ABSTRACT}

Head and neck cell squamous-cell carcinomas (HNSCC) are a group of common cancers typically associated with tobacco use and human papilloma virus infection. Up to half of all cases will suffer a recurrence after primary treatment. As such, new therapies are needed, including therapies which promote the anti-tumor immune response. Prior work has characterized changes in the mutation burden between primary and recurrent tumors; however, little work has characterized the changes in neoantigen evolution. We characterized genomic and neoantigen changes between 23 paired primary and recurrent HNSCC tumors. Twenty-three biopsies from patients originally diagnosed with locally advanced disease were identified from the Washington University tumor bank. Whole exosome sequencing, RNA-seq, and immunohistochemistry was performed on the primary and recurrent tumors. Within these tumors, we identified 6 genes which have predicted neoantigens in 4 or more patients. Interestingly, patients with neoantigens in these shared genes had increased CD3 + CD8 + T cell infiltration and duration of survival with disease. Within HNSCC tumors examined here, there are neoantigens in shared genes by a subset of patients. The presence of neoantigens in these shared genes may promote an anti-tumor immune response which controls tumor progression.

\section{INTRODUCTION}

Head and neck cancer are a group of heterogeneous tumors with an estimated 644,000 new cases per year worldwide [1]. Head and neck cancers represent 3\% of all new cancer cases and 2\% of all cancer-related deaths. Most head and neck cancers have squamouscell carcinoma morphology (HNSCC). Risk factors for HNSCC include tobacco use and human papilloma virus (HPV) infection [2]. In locally advanced disease, current therapies include combinations of resection, radiotherapy, and chemotherapy [3]. Although these treatments may lead to cure, relapse of disease occurs in $30-50 \%$ of patients $[4,5]$.

Current therapies for relapsed or metastatic HNSCC include immunotherapy, chemotherapy, or cetuximab [6]. Immunotherapy was shown to prolong overall survival in comparison to chemotherapy given with or without cetuximab [7-10]. A relatively new FDA-approved type of therapy for HNSCC are immune checkpoint inhibitors. Immune checkpoint molecules, such as PD-1, PD-L1, and CTLA-4, are surface molecules on the surface of activated 
immune cells [11]. The binding of PD-1 to PD-L1 or CTLA-4 to CD80/CD86 inhibits the immune response. By blocking the binding of these checkpoint molecules, the immune response against the tumor is licensed to continue.

The efficacy of checkpoint inhibitors in HNSCC indicates a role for the immune system in the control and elimination of this disease. The infiltration of immune cells, including $\mathrm{T}$ cells, into tumor is associated with improved outcomes and longer survival in HNSCC [1217]. The infiltrating $T$ cells release granules containing perforin and granzyme A and B which directly kill tumor cells or release other cytokines and chemokines that promote the anti-tumor immune response and alter the tumor microenvironment [18]. For example, infiltrating $\mathrm{T}$ cells release interferon gamma which increases expression of PD-L1 and CTLA-4, which may increase the efficacy of immune checkpoint therapy [19, 20].

During the progression of cancer, there is an increased mutational burden. These mutations can result in the development of neoantigens. These neoantigens may mark some clones for immunoediting and elimination. However, the clones which escape immunoediting are the source of cancer cell persistence, relapse, and metastasis. Multiple studies have characterized changes in mutation burden in HNSCC [21-24], when comparing primary and metastatic tumors, no studies have characterized the shifting neoantigen burden between primary and metastatic tumors within HNSCC. In this study, we characterized the mutational and neoantigen burden between primary and first recurrence tumors in 23 patients with HNSCC. In this analysis, primary and recurrent tumors were identified that had neoantigens in shared genes in multiple patients. These patients had increased CD8+ cell infiltration and increased expression of cytolytic gene expression. This study provides the justification for looking at a larger dataset in a prospective manner for the identification of recurrent neoantigens in the evolution of HNSCC.

\section{RESULTS}

\section{Patient demographics}

Twenty-three HNSCC patients were identified that were consented to the Washington University tumor bank and had genetic material available for germline, primary tumor and first recurrence/metastases (patient characteristics are listed in Table 1). Males represented 17 of 23 patients (74\%) of the patient population. Tobacco smokers represented 14/23 (61\%), 7 (30\%) patients were non-smokers, 1 (4\%) patient chewed tobacco and $1(4 \%)$ patient smoked marijuana. Primary tumors are in the oral cavity $(9 / 23,39 \%)$, oropharynx $(7 / 23,30 \%)$, larynx $(6 / 23,26 \%)$, and hypopharynx $(1 / 23,4 \%)$. All seven oropharyngeal patients $(7 / 23,30 \%)$ were positive for the human papilloma virus (HPV+). All of these percentages are similar to those reported in the cancer genome atlas
[25]. In our patient population, 20 of the 23 patients ( $87 \%)$ received radiation, 13 of $23(57 \%)$ received cisplatin, 7 of the 23 patients (30\%) received no chemotherapy, and 3 of 23 patients (13\%) received Cetuximab (Table 2).

\section{Sequencing data and bioinformatics workflow}

Of the 23 patients, we sequenced 23 blood samples for germline WES data and 46 paired primary and recurrent/metastatic samples from paraffin blocks to generate WES data, and performed RNA-Seq successfully for 31 samples (Figure 1 and Methods). Next, we generated clean data for downstream analysis based on a standard pipeline. To call high confidant mutations from 46 paired tumor-germline WES data, we used four somatic mutation tools to call mutations and filtered false-positive mutations via bam-readcount tool. Of the RNA-Seq data, for 16 primary tumors and 15 recurrent/metastatic tumors gene expression was predicted using kallisto [26] (Figure 1). To predict neoantigens, we utilized OptiType [27] and MuPeXI [28] to define candidate neoantigens for 46 tumor samples.

\section{Comparison of somatic mutations between primary and recurrent/metastatic}

Based on the WES, total somatic mutations were identified for each of the patients. Patients were sorted by patients with the highest neoantigen burden. Patients H004, H003, H002, H008, H011, H018, and H014 have the greatest number of total somatic mutations compared with other patients (Figure 2A). Interestingly, three of the patients have a primary tumor in the larynx (Patients $\mathrm{H} 004, \mathrm{H} 003$, and H011) and 3 patients (H008, H018, and H014) have a primary tumor in the oropharynx. There is a general trend that the recurrent/metastatic tumor has more mutations than the primary tumor (Figure 2A). The majority of all somatic mutations are missense mutations and silent mutations. To understand the recurrent mutation effect between primary and recurrent/metastatic tumors, we extract recurrently mutated genes ( $>1$ sample mutated gene) from primary and recurrent/metastatic samples, separately. We detected 536 and 786 recurrently mutated genes from primary and recurrent/metastatic samples, respectively (Figure 2B). Of them, 319 genes shared both of primary and recurrent/metastatic tumors.

We next performed KEGG pathways (http://www. webgestalt.org) analysis to determine if somatic mutations were in pathways related to metastasis. Of them, most of the significant gene enrichment pathways tend toward the relapse due to the generally higher number of mutations in the recurrent/metastatic compared to the primary samples (Figure 2B). Of them, $\mathrm{ABC}$ transporters, Adherens junction, cAMP signaling, and Taste transduction pathways were significant only in recurrent/metastatic samples, and extracellular matrix (ECM)-receptor 
interaction, Human papillomavirus infection, and PI3KAkt signaling pathways were significant in both of primary and recurrent/metastatic samples. Notably, ECMreceptor interaction pathway was extremely significant in recurrent/metastatic samples meaning that genes related to this pathway are more highly mutated than other pathway mutations in recurrent/metastatic samples. ECM-receptor interaction signaling pathway plays a crucial role in modulating breast cancer metastases [29, 30]. We then checked driver gene inflection for primary and recurrent/ metastatic samples via 299 known driver genes [31]. Figure $2 \mathrm{C}$ demonstrates the high frequency of mutations in the top 20 driver genes. TP53 gene is the highest mutated driver gene in both sample groups. We further identified differential mutations in the driver genes between the primary and recurrent/metastatic tumors. In doing so, we identified that BRCA1 and NOTCH1 driver genes are highly mutated in primary samples, and $P I K 3 C A$, ARID1A, RASA1, TSC2, and ERBB4 were mutated higher in recurrent/metastatic compared with primary samples. Especially, CIC, KIF1A, LATS1, RARA, SPTAN1 genes only mutated in recurrent/metastatic samples (Figure 2D).

\section{Immune cell infiltration}

To determine the infiltration of immune cells into the primary and recurrent/metastatic tumors, immunohistochemistry (IHC) was performed. There is no difference in the infiltration of CD3+ cells (Figure 3A), activated T cells (CD3+ HLA-DR+) (Figure 3B), cytotoxic T cells (CD3+ CD8+) (Figure 3C), or CD3+ FOXP3+ cells (Figure $3 \mathrm{D}$ ) between the primary and recurrent tumor. IHC was also used to determine the surface expression of PD-L1 on tumor cells. There was a significant increase in the tumor expression of PD-L1 between the primary and recurrent/metastatic tumors (Figure $3 \mathrm{E}$ ).

\section{Gene expression patterns for immune check point genes}

Eleven pairs of primary and recurrent/metastatic tumors were further determined using Kallisto [26]. There is a significant reduction in the expression of the antigen presenting genes $B 2 M, H L A-A, H L A-B$, and $H L A-C$ in the recurrent/metastatic tumors relative to the primary tumors (Figure 4). To confirm the immunohistochemistry results, the expression of $C D 3 E, H L A-D R A, C D 8 A$, and FOXP3 was examined in the primary and recurrent/metastatic tumors. There was a decrease in the expression of all four of these genes in the recurrent/metastatic tumors, relative to the primary tumors. Only $H L A-D R A$ was significantly decreased. Cytolytic (CTL) activity is the geometric mean of the expression of perforin and granzyme A [32]. There was no change in the expression of CTL activity between the primary and recurrent/metastatic tumors. The expression of CD274 (gene for PD-L1) was significantly

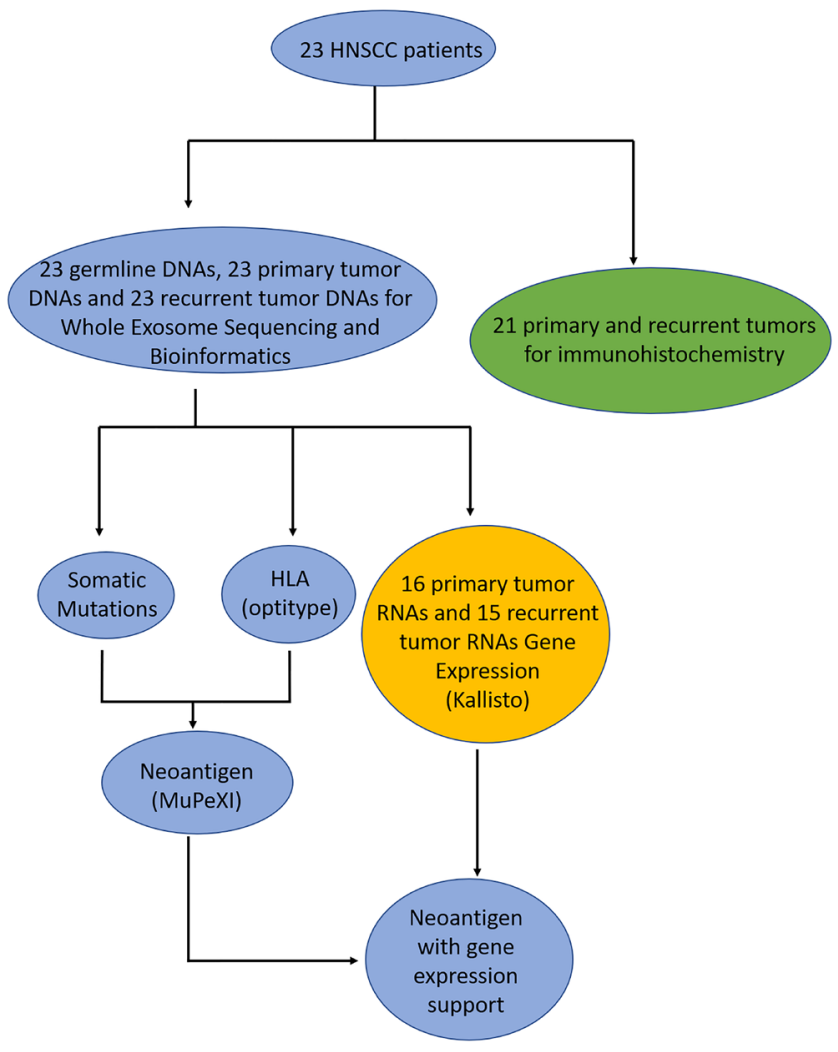

Figure 1: Flowchart of patient samples. The blue circles are the samples where DNA was sequenced and analyzed, green circles are the samples where immunohistochemistry was performed, and yellow are the samples where had RNA sequenced and analyzed. 
Table 1: Patient demographics

\begin{tabular}{|c|c|c|c|c|c|}
\hline Anatomic site & P16_status & Smoking History & Gender & Stage & Patient ID \\
\hline Oropharynx & Positive & 15 Pack-years & Male & Stage IVB T4bN2cM0 & 001 \\
\hline Oropharynx & Positive & Marijuana 1 Pack-years & Male & Stage IVA T2N2bM0 & 007 \\
\hline Oropharynx & Positive & Non-smoker & Male & Stage IVA T2N2bM0 & 008 \\
\hline Oropharynx & Positive & 45 Pack-years & Male & Stage IVA T4aN2bM0 & 014 \\
\hline Oropharynx & Positive & 10 Pack-years & Male & Stage IVA T1N2bM0 & 017 \\
\hline Oropharynx & Positive & Non-smoker & Male & Stage IVA T3N2bM0 & 018 \\
\hline Oropharynx & Positive & Non-smoker & Male & Stage IVA T2N2bM0 & 021 \\
\hline Hypopharynx & Negative & 45 Pack-years & Male & Stage IVA T2N2aM0 & 005 \\
\hline Larynx & Negative & 70 Pack-years & Male & Stage IVA T3N2M0 & 003 \\
\hline Larynx & Negative & 14 Pack-years & Male & Stage IVA T3N3M0 & 004 \\
\hline Larynx & Negative & Chew for 42 years & Male & Stage I T1N0M0 & 009 \\
\hline Larynx & Negative & 50 Pack-years & Female & Stage IVA T3N2bM0 & 011 \\
\hline Larynx & Negative & 33 Pack-years & Female & Stage III T3N1M0 & 019 \\
\hline Larynx & Negative & 68 Pack-years & Male & Stage III T2N1M0 & 013 \\
\hline Oral cavity & Negative & 38 Pack-years & Male & Stage IVA T3N2M0 & 002 \\
\hline Oral cavity & Negative & Non-smoker & Male & Stage IVA T2N2bM0 & 010 \\
\hline Oral cavity & Negative & 70 Pack-years & Male & Stage IVA T4N2bM0 & 012 \\
\hline Oral cavity & Negative & 50 Pack-years & Male & Stage III T3N1M0 & 016 \\
\hline Oral cavity & Negative & 50 Pack-years & Male & Stage IVA T4N2cM0 & 020 \\
\hline Oral cavity & Negative & Non-smoker & Male & Stage III T2N1M0 & 024 \\
\hline Oral cavity & Negative & Non-smoker & Female & Stage IVA T2N2bM0 & 006 \\
\hline Oral cavity & Negative & 15 Pack-years & Female & Stage III T2N1M0 & 015 \\
\hline Oral cavity & Negative & Non-smoker & Female & Stage III T3NXM0 & 023 \\
\hline
\end{tabular}

increased in the recurrent/metastatic tumors relative to the primary tumors, similar to the immunohistochemistry results in Figure 3. Finally, the expression of the checkpoint molecules PDCD1 (gene for PD-1) and CTLA4 were examined. There was a decrease in the expression of both molecules, and PDCD1 was significantly decreased (Figure 4).

\section{Landscape of HLA genotypes and neoantigens}

HLA types for each patient were determined with OptiType [27], and the most common HLA type was HLA-A*02:01, which was present in almost half (11/23) of patients (Figure 5A). Other common HLA types include HLA-C 07:01 (9/23 patients), HLA-A*01:01 (7/23), and HLA-B*08:01 (7/23). Using the data from somatic mutations and HLA genotypes, neoantigens were predicted using MuPeXI [28]. Patients H004, H003, H002, $\mathrm{H} 008$, H011, H018, and H014 had the highest neoantigen burden (Figure 5B). These are the same patients who had large numbers of somatic mutations in Figure 2A. While there were specific neoantigens in either the primary or the recurrent/metastatic tumor, there was a trend toward more neoantigens in the recurrent/metastatic compared to the primary tumors (Figure 5B). We next sought to determine if genes containing neoantigens were shared between patients. Most neoantigens were unique to an individual tumor. While there were some genes containing neoantigens that were shared between 2 or 3 patients, a total of five genes with neoantigens were shared by 4 or 5 patients (Figure 5C). Of these genes, three (RYR3, DNAH7, and $T T N)$ were identified from the primary tumors. There were three genes (PIK3CA, USH2A, and TTN) containing neoantigens in the recurrent/metastatic tumors. A summary of the number of predicted neoantigens from each of the identified genes from each patient are listed in Table 3. The amino acid sequence for the predicted neoantigen and the predicted HLA presenting the neoantigen are listed in Supplementary Table 1. It is important to note that while the genes which share the neoantigens are shared between patients, the predicted neoantigen peptides are unique to each patient because the mutations varied between patients. There is one peptide sequence shared between patients. Both Patient 001 and 018 have a predicted neoantigen from 
Table 2: Patient treatments

\begin{tabular}{|c|c|c|c|c|}
\hline Genome ID & Anatomic site & Treatment Type & Chemotherapy & Radiation Therapy \\
\hline HNSCC-001 & Oropharynx & definitive & cisplatin & Yes \\
\hline HNSCC-007 & Oropharynx & post-operative & cisplatin & Yes \\
\hline HNSCC-008 ${ }^{\mathrm{a}}$ & Oropharynx & Surgery only & none & No \\
\hline HNSCC-014 & Oropharynx & post-operative & cisplatin & Yes \\
\hline HNSCC-017 & Oropharynx & post-operative & cisplatin & Yes \\
\hline HNSCC-018 & Oropharynx & post-operative & None & Yes \\
\hline HNSCC-021 & Oropharynx & post-operative & cisplatin & Yes \\
\hline HNSCC- $005^{\mathrm{b}}$ & Hypopharynx & Surgery only & None & No \\
\hline HNSCC-003 & Larynx & post-operative & None & Yes \\
\hline HNSCC-004 & Larynx & definitive & cisplatin & Yes \\
\hline HNSCC-009 & Larynx & definitive & None & Yes \\
\hline HNSCC-011 & Larynx & post-operative & cisplatin & Yes \\
\hline HNSCC-019 & Larynx & neoadjuvant & $\begin{array}{l}\text { abraxane } / 5 \mathrm{FU} / \text { cisplatin; } \\
\text { cisplatin with RT }\end{array}$ & Yes \\
\hline HNSCC-013 & Larynx & post-operative & cisplatin & Yes \\
\hline HNSCC-002 & Oral Cavity & post-operative & taxol/cetuximab & Yes \\
\hline HNSCC-010 & Oral Cavity & post-operative & cetuximab & Yes \\
\hline HNSCC-012 ${ }^{\mathrm{c}}$ & Oral Cavity & Surgery only & None & No \\
\hline HNSCC- $016^{\mathrm{d}}$ & Oral Cavity & post-operative & cisplatin & Yes \\
\hline HNSCC-020 & Oral Cavity & post-operative & cisplatin & Yes \\
\hline HNSCC-024 & Oral Cavity & post-operative & cisplatin & Yes \\
\hline HNSCC-006 & Oral Cavity & post-operative & None & Yes \\
\hline HNSCC-015 & Oral Cavity & post-operative & cisplatin & Yes \\
\hline HNSCC-023 & Oral Cavity & post-operative & cetuximab & Yes \\
\hline
\end{tabular}

${ }^{a}$ no adjuvant treatment given. ${ }^{b} 2$ nd primary for $\mathrm{H} \& \mathrm{~N}$. ${ }^{\mathrm{c}}$ developed lung metastasis before adjuvant treatment could start. ${ }^{\mathrm{d}}$ patient stopped treatment early.

533-542 of PIK3CA in their recurrent tumor. Both patients have a mutation to lysine at position 542 .

To determine if the predicted neoantigens were a result of HLAs found in this patient population, we looked at the distribution of the HLAs predicted to present neoantigens from the shared genes (Figure 5D). A total of 14 of the 23 patients are represented in this group. Four patients had neoantigens predicted in primary tumors to be displayed on HLA-A*02:01, and two patients had had neoantigens in the recurrent tumor displayed on this haplotype. Three patients with mutations in recurrent tumors were presented on HLA-B*08:01 and three patients had primary tumor neoantigens predicted to be displayed on HLA-B*07:02. These are on the only other haplotypes utilized by more than 2 patients. This suggests that the presence of neoantigens in these shared genes are not a result of HLA distribution in this population.

\section{Neoantigens and CTL activation}

We sought to determine the effect of these neoantigens in shared genes on the patient. Patients with neoantigens in these shared genes tend toward higher overall neoantigen burden compared to those without neoantigens in these shared genes (Figure 6A). In primary tumors, patients with neoantigens in RYR3 and DNAH7 have significantly more total neoantigens compared to patients without neoantigens in these shared genes. The duration of survival with disease was also increased in patients with these neoantigens in shared genes compared to those without (Figure 6B). Without neoantigens in shared genes, the mean duration of survival with disease is 1,200 days. There was a non-significant increase in the patients with neoantigens in shared genes ranging from 1,382-2,052 days. This increase in the duration of survival with disease 
Table 3: Number of neoantigens in selected genes

\begin{tabular}{|c|c|c|c|c|c|c|c|}
\hline Anatomic site & $\begin{array}{c}\text { Patient } \\
\text { ID }\end{array}$ & $\begin{array}{c}\text { RYR3 } \\
\text { Primary }\end{array}$ & $\begin{array}{l}\text { DNAH7 } \\
\text { Primary }\end{array}$ & $\begin{array}{c}\text { TTN } \\
\text { Primary }\end{array}$ & $\begin{array}{c}\text { TNN } \\
\text { Recurrent }\end{array}$ & $\begin{array}{c}\text { PIK3CA } \\
\text { Recurrent }\end{array}$ & $\begin{array}{c}\text { USH2A } \\
\text { Recurrent }\end{array}$ \\
\hline Oropharynx & 001 & & & & & 1 & \\
\hline Oropharynx & 007 & 9 & & & & & \\
\hline Oropharynx & 008 & & 3 & & & 3 & \\
\hline Oropharynx & 014 & & & & & 2 & \\
\hline Oropharynx & 017 & & 8 & & & & \\
\hline Oropharynx & 018 & 4 & & 7 & 6 & 3 & \\
\hline Oropharynx & 021 & & & & & & \\
\hline Hypopharynx & 005 & & & & & & \\
\hline Larynx & 003 & 5 & 2 & & 1 & & 3 \\
\hline Larynx & 004 & 9 & 1 & 7 & 11 & & 5 \\
\hline Larynx & 009 & & & & & & \\
\hline Larynx & 011 & & & & & & \\
\hline Larynx & 019 & & & 5 & & & 1 \\
\hline Larynx & 013 & & & & & & 2 \\
\hline Oral cavity & 002 & & 3 & & & & \\
\hline Oral cavity & 010 & & & & & & \\
\hline Oral cavity & 012 & & & & & & 2 \\
\hline Oral cavity & 016 & & & 4 & & 2 & \\
\hline Oral cavity & 020 & & & & 4 & & \\
\hline Oral cavity & 024 & & & & & & \\
\hline Oral cavity & 006 & & & & & & \\
\hline Oral cavity & 015 & & & & & & \\
\hline Oral cavity & 023 & & & 3 & 3 & & \\
\hline
\end{tabular}

may be related to higher infiltration of CD3 + CD8 + cells as determined by IHC (Figure 6C). In the primary tumor, there are no significant changes in CD3+CD8+ density. In the recurrent/metastatic tumors, patients with neoantigens in TTN, PIK3CA, and USH2A increased CD3+ CD8+ infiltration approximately 3-fold compared to patients without neoantigens in these genes. The expression of $C D 8 A$ was increased in primary tumors with neoantigens in RYR3 and DNAH7 and in recurrent/metastatic tumors with neoantigens in TTN and PIK3CA (Figure 6D). CTL activity trended to be increased in patients with the neoantigens in RYR3 and DNAH7 in primary tumors and neoantigens in $T T N$ and $P I K 3 C A$ in recurrent/metastatic tumors (Figure $6 \mathrm{E})$. This is notable given there was no change in CTL activity in between primary and recurrent/metastatic tumors (Figure 4), but the sample size is small.

\section{DISCUSSION}

In this study, we sequenced the primary and the recurrent/metastatic tumor from $23 \mathrm{HNSCC}$ patients and found an expected increase in the number of mutations in the recurrent/metastatic tumors compared to the primary tumors. By IHC, we found no differences in the infiltration of immune cells, however the recurrent/ metastatic tumors had decreased expression of the antigen presenting genes, B2M, HLA-A,HLA-B, HLA-C, and HLA$D R$, and the checkpoint molecule $P D C D 1$ and increased $C D 274$ expression compared to the primary tumors. Most importantly, we identified neoantigens in the recurrent genes in four-five patients. These patients have increased total neoantigens, and a trend toward increased duration of survival with disease, infiltration of CD8 cells, and CTL activity. This suggests HNSCC neoantigens can stimulate an anti-tumor immune response.

For the primary and recurrent/metastatic HNSCC tumors, there is an increased mutational burden. It is interesting that the number of mutations is not simply increasing from the primary to the recurrent/metastatic tumor, but they are changing, with the primary and recurrent/metastatic tumors having unique sets of mutations. While the change in mutational burden 
will have implications for the neoantigen burden, the alteration of mutational burden will have impacts on the biology of the tumor and on tumor metastasis. For example, the upregulation of the PI3K can upregulate matrix metalloproteins and upregulation of extracellular matrix-receptor pathways are associated with metastasis and invasion [21, 22, 24].

Next, we examined the infiltration of T cells into the tumor with immunohistochemistry and gene expression.
The expression of MHC I genes (B2M, HLA-A,HLA-B, and $H L A-C$ ) were decreased significantly. This suggests the ability to present antigens to the infiltrating immune cells is decreased in the recurrent/metastatic compared to the primary tumor. Despite this decrease in MHC I gene expression, this does not correspond to changes in the $\mathrm{T}$ cell infiltration. By IHC, there were no significant changes in the infiltration of any examined $\mathrm{T}$ cell population in primary and recurrent/metastatic tumors. This is

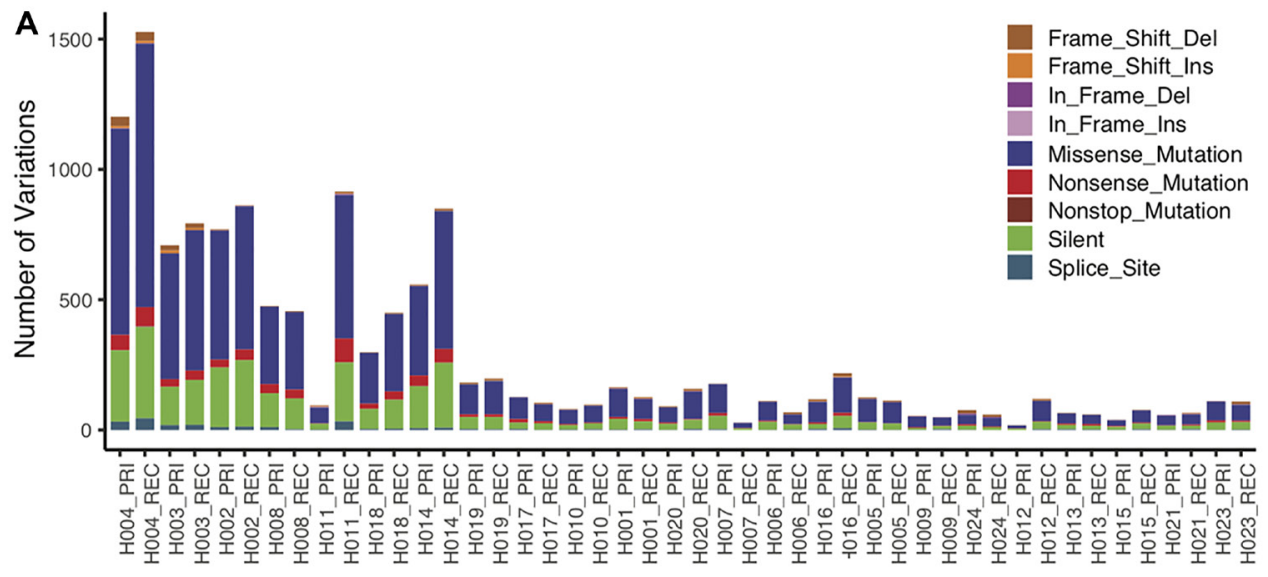

B

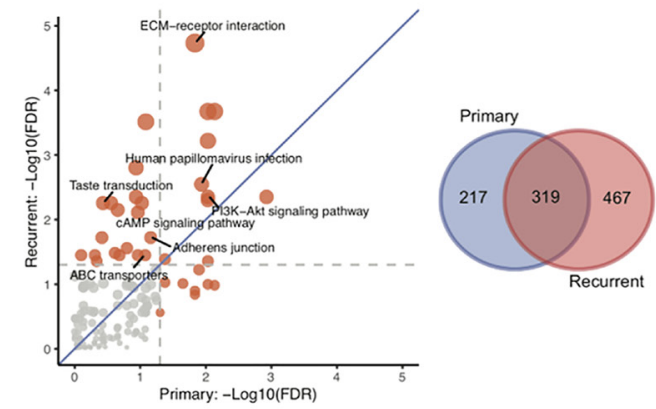

C

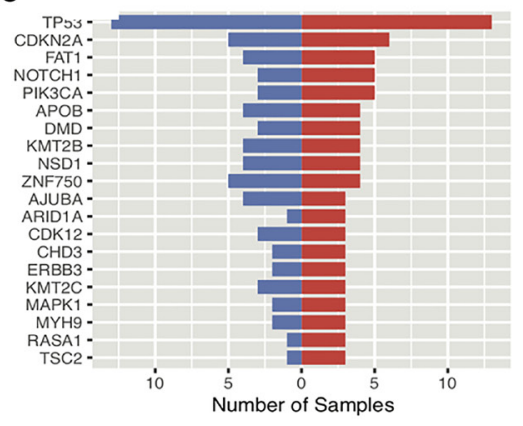

D

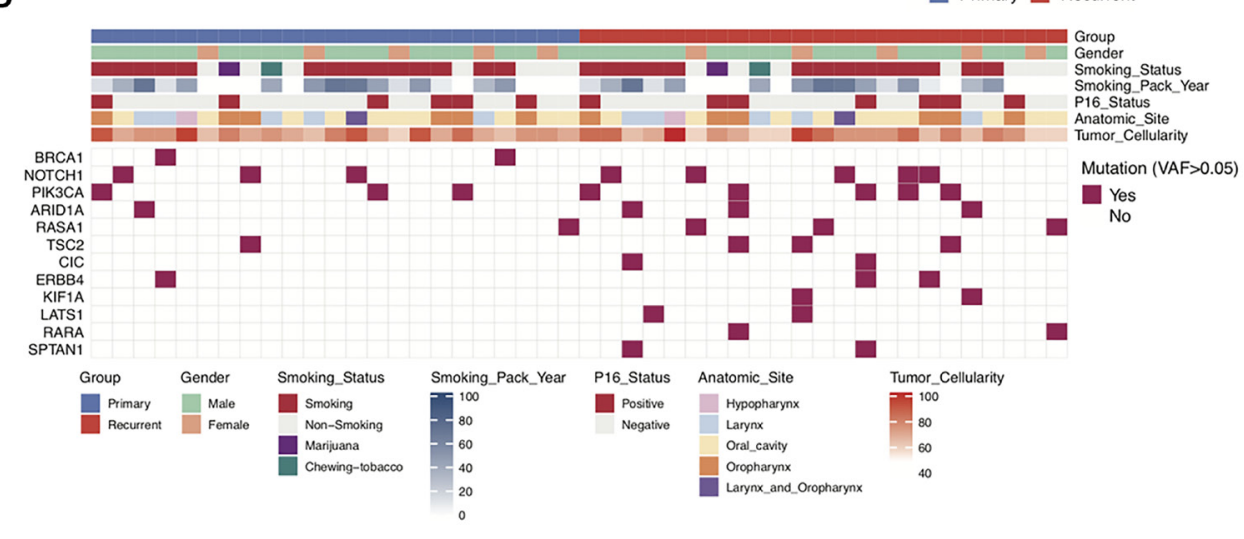

Figure 2: Characterization of DNA sequences of primary and recurrent/metastatic tumors. (A) Based on DNA sequencing of 23 paired primary and recurrent/metastatic tumors, the total number of somatic mutations for each patient primary and recurrent/ metastatic tumor. The different mutation types are indicated in different colors. (B) Based on the sequencing from all 23 paired primary and recurrent/metastatic tumors, KEGG pathways was used to determine which pathways are enriched for mutations in either the primary or the recurrent/metastatic tumor. The Venn Diagram is of the total number of recurrent mutations in the primary tumor alone, recurrent/metastatic tumor alone, or shared. (C) The number of patients with mutations in the top 20 most frequently mutated driver genes in both the primary and the recurrent/metastatic tumors. (D) Distribution of mutations in driver genes. In both the primary and recurrent/metastatic tumor, the variant allele frequency is greater than 0.5 is indicated for each patient. 
consistent with the gene expression of $C D 3 E$ which also is unchanged between the primary and recurrent/metastatic tumor. While the expression of HLA-DR on T cells is a marker of activation [33, 34], the expression of $H L A-D R A$ is significantly reduced. HLA-DR is expressed from other immune cells (such as antigen presenting cells), suggesting the decreased expression of the total tumor is due to the downregulation of $H L A-D R A$ in other cells. Interestingly, down-regulation of HLA-DRA is also associated with non-activated antigen presenting cells.
Beyond the infiltration of the cells, CTL activity (geometric mean of perforin and granzyme A expression) is not noticeably different between the primary and the recurrent/metastatic tumors. So, there is no change in either the infiltration of CD3+ CD8+ cells or cytolytic activity. Lastly, by immunohistochemistry, CD3+ FOXP3 + cells and by RNA-Seq, FOXP3 expression is not significantly changed between the primary and recurrent/ metastatic tumor. This suggests that the infiltration of $\mathrm{T}$ cells in general and more specifically cytotoxic $\mathrm{T}$ cells and
A

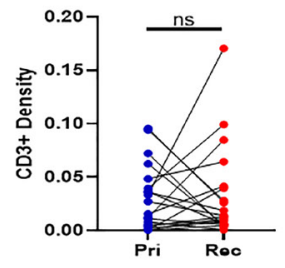

B

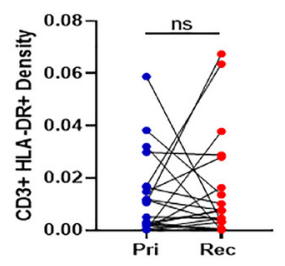

C

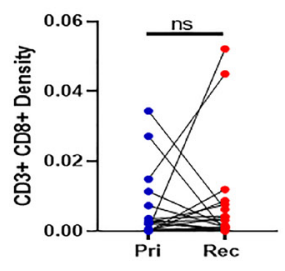

D

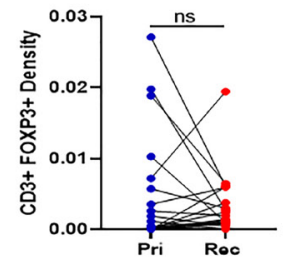

E

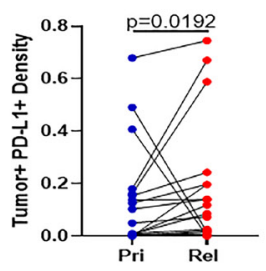

Primary
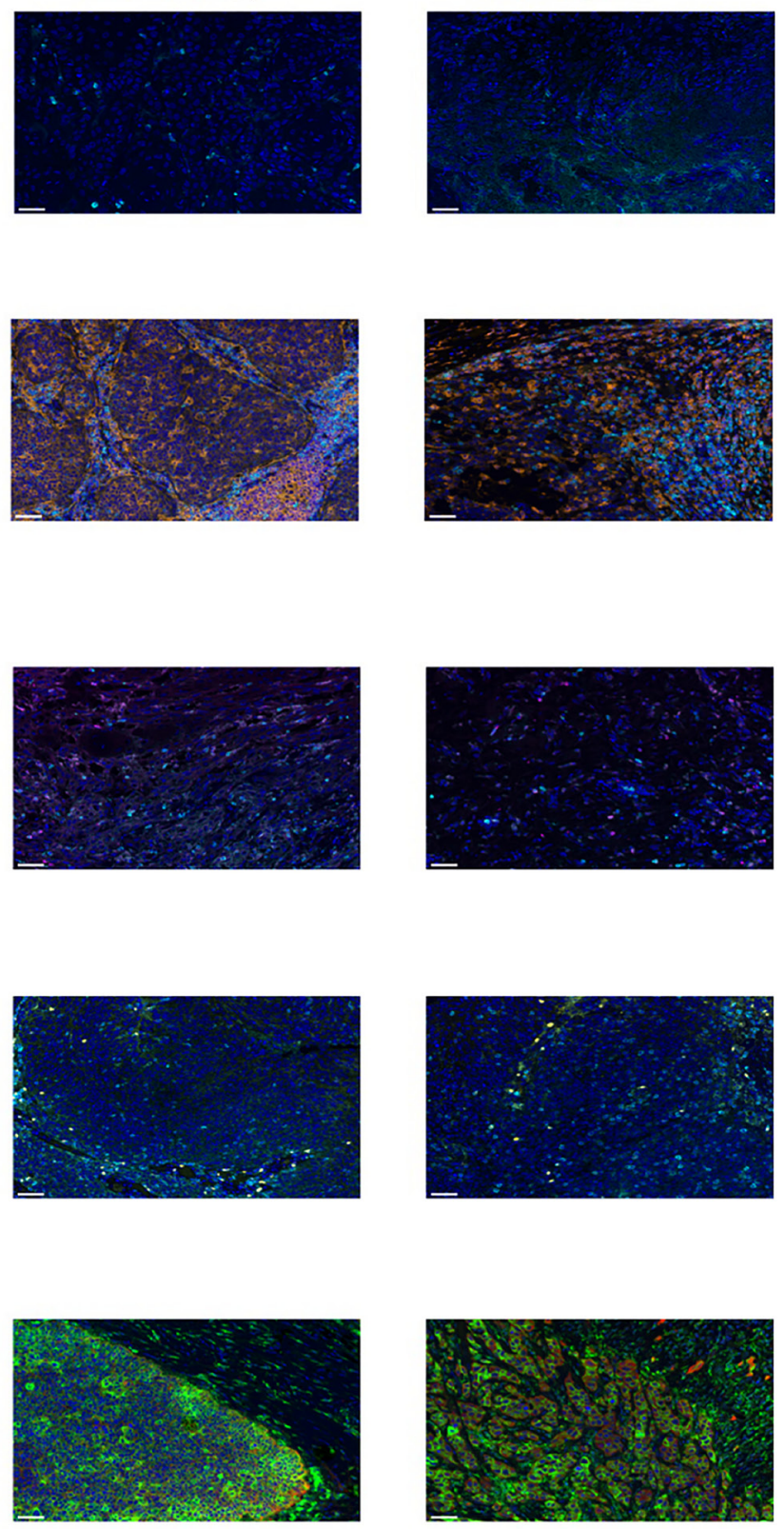

Figure 3: Immunohistochemistry of $\mathbf{T}$ cell infiltration into the tumor. Twenty paired blocks from the primary and relapse tumor were stained for (A) CD3+ (cyan), (B) CD3+ (cyan) HLA-DR+ (orange), (C) CD3+ (cyan) CD8+ (magenta), (D) CD3+ (cyan) Foxp3+ (yellow), and (E) Tumor+ (Pan Cytokeratin red) PD-L1+ (green). All sections contain DAPI (blue). The density of the paired samples are graphed. Significance was determined using a paired $t$ test with. A $p$-value is significant if it is less than 0.05 , ns $=$ not significant. Images are $20 \times$ magnification and the scale bar is $50 \mu \mathrm{m}$. 
Tregs are not different between the primary and recurrent/ metastatic tumors. However, we did not examine other immune cell populations. More work is needed to further determine the different immune populations within the tumor. It would be interesting to determine the infiltration of other immune cell populations and approximate the activation state of these cells, but this would require a larger data set.

We also tested the expression of check point molecules by IHC and gene expression. PD-L1 is significantly increased on tumor cells by IHC. This increase is reflected by significantly increased expression of CD274 in the tumor. Both PDCD1 (gene for PD-1) and
CTLA4 are decreased in the recurrent/metastatic tumor compared to the primary tumor. As has been previously described, the expression of check point molecules, in particular PD-L1, is important for determining the efficacy of check point inhibition therapy $[7,8]$. The observation that the expression of these checkpoint molecules changes between the primary and recurrent/metastatic tumors has potential implications for therapeutic development. While additional studies are needed, these results suggest that changes to check point molecule expression may facilitate the relapse of HNSCC.

It is not surprising that the patients with highest numbers of total somatic mutations have the highest
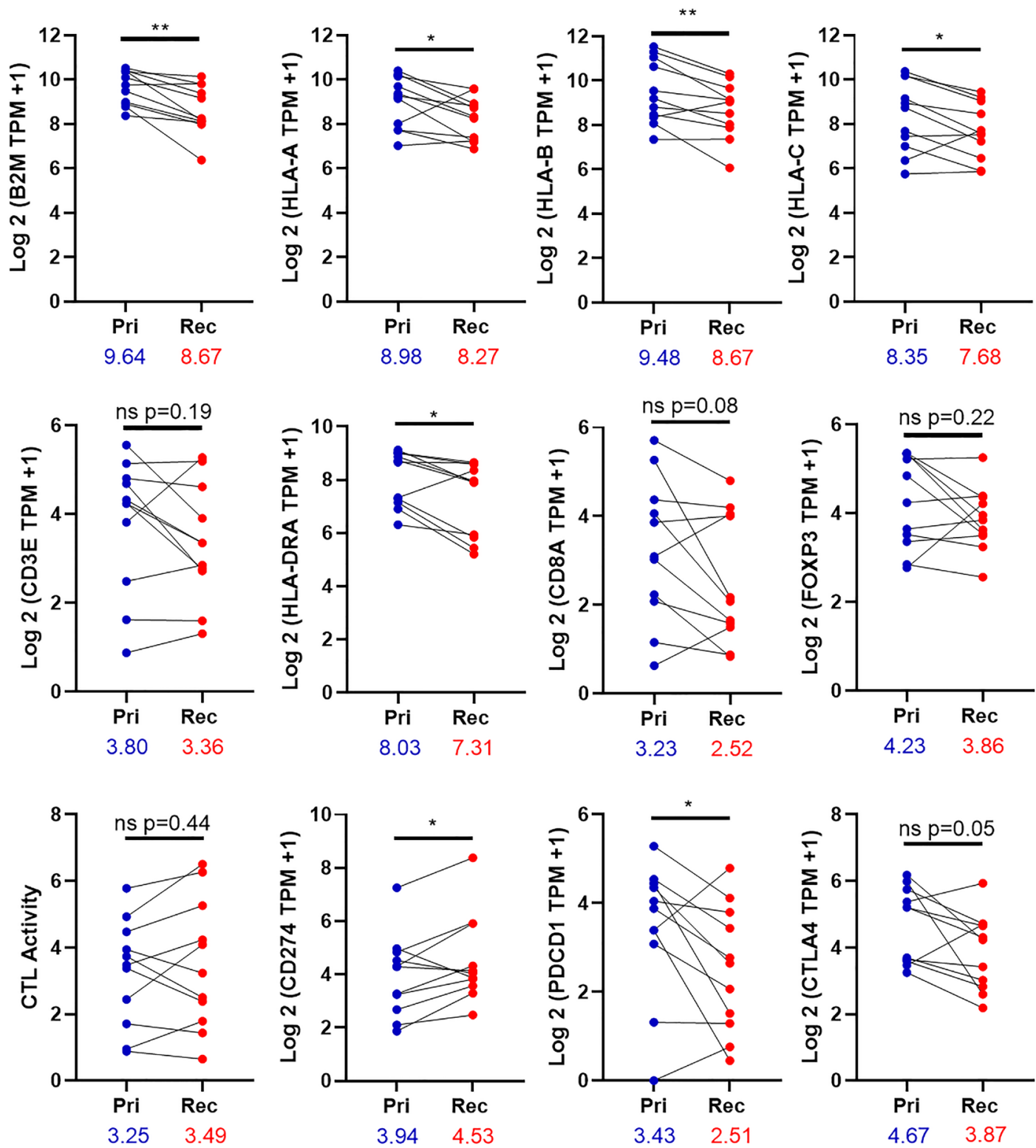

Figure 4: Expression of immune genes in the tumor. The expression of 11 paired primary and relapse tumors was determined by the equation $\log 2$ (TPM of the indicated gene +1 ). CTL activity is the geometric mean for the expression of Granzyme A and Perforin. Pri-primary tumor, Rec-Recurrent/metastatic tumor. Significance was determined using a paired $t$ test with. A $p$-value is significant if it is less than $0.05 .{ }^{*}$ denoted $p$-value $<0.05^{* *}$ denotes $p$-value $<0.01$, ns $=$ non-significant. The numbers under the $\mathrm{X}$-axis are mean of gene expression. 
neoantigen burden. As with somatic mutations, many neoantigens are shared between the primary and recurrent/ metastatic tumor. However, there is a shifting neoantigen burden as there are unique neoantigens in primary tumors and different unique neoantigens in the recurrent/ metastatic tumors. Interestingly, there are neoantigens in genes shared between up to five of the 23 patients. The patients which have these neoantigens in shared genes are patients which have higher total numbers of neoantigens. As such, it is not clear if the differences identified are due to the specific neoantigens or to the increased total number of neoantigens. What is clear is that patients with neoantigens in these shared genes also tend to have increased duration of survival with disease. The increased survival may not have been statistically significant, but the increased survival for more than 100 days would be noticeable for the life of the patient. While much more work is needed to expand on these

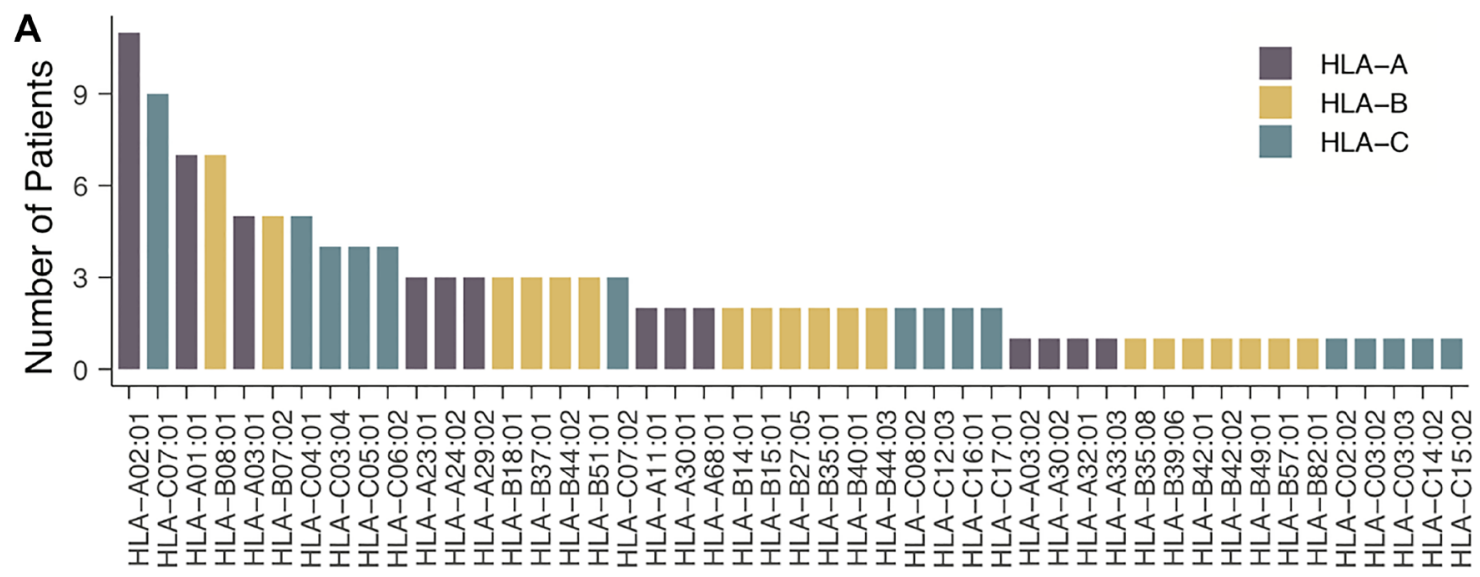

B

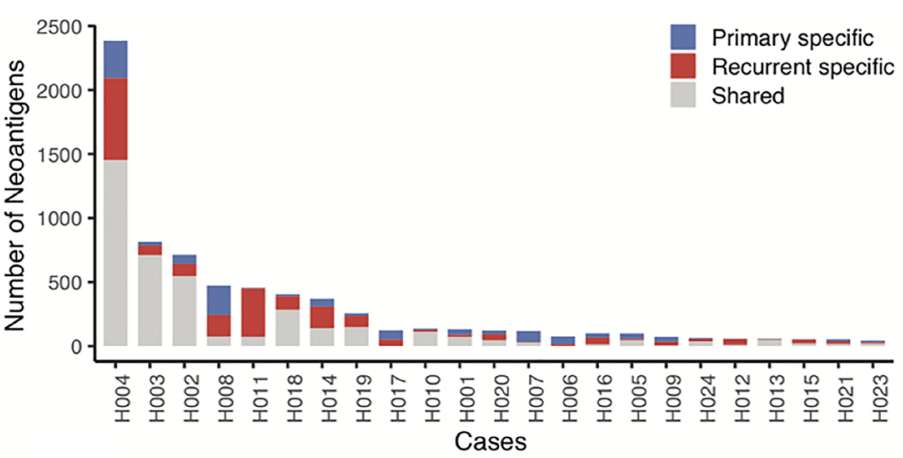

D

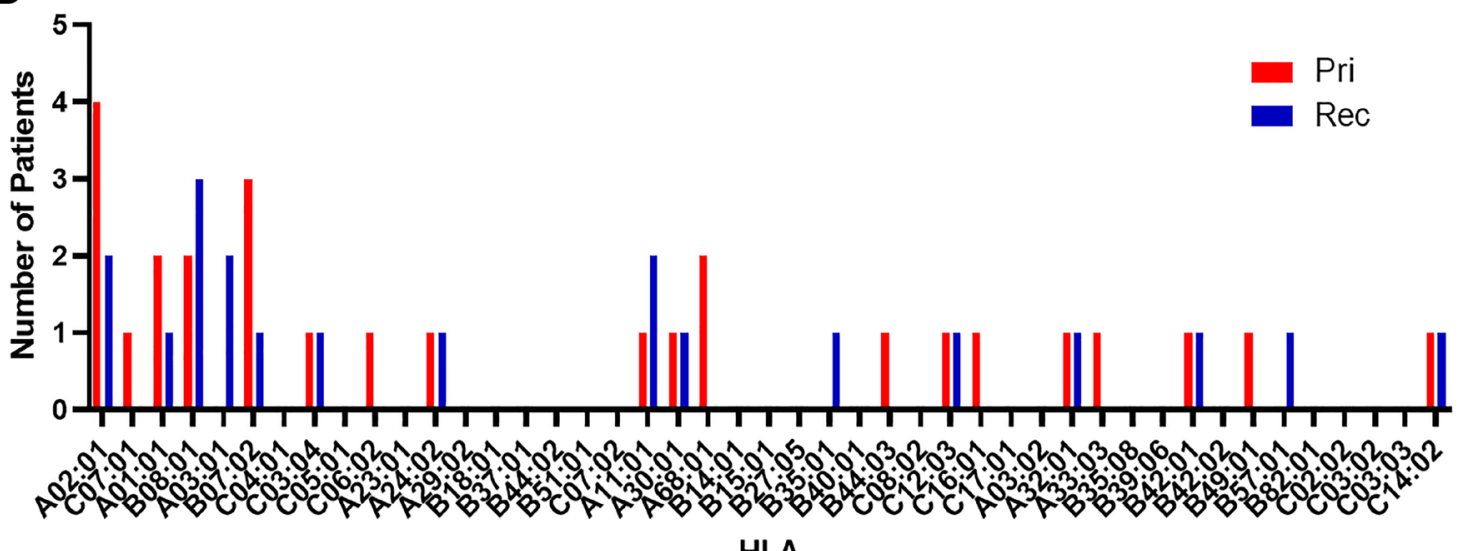

Figure 5: Neoantigen burden and evolution. (A) For the 23 patients for which there was DNA, the number of patients expressing HLA-A, -B, and $-\mathrm{C}$ alleles in the patient population. (B) For 23 patients, the total number of neoantigens predicted in the primary tumor alone (Blue), relapse tumor alone (Red), and shared (Gray). (C) The number of predicted neoantigens for each gene was graphed by the number of patients sharing those neoantigens. (D) For the patients with neoantigens in shared genes, the number of patients with HLAs predicted to present neoantigens. Neoantigens in primary tumors are in red, neoantigens in recurrent tumors are in blue. 
results, the observation that five patients in this relatively small sample have neoantigens in the shared genes is remarkable. The increase in neoantigens and duration of survival with disease tends to be associated with increased $\mathrm{CD} 3+\mathrm{CD} 8+$ density in the tumor and CD8A expression. More interestingly, there is a trend toward increased in CTL activity in the patients with shared neoantigens. This suggests that patients with these shared neoantigens are associated with increased CD8 $+\mathrm{T}$ cell infiltration and increased cytotoxic activity, which extends the patient's life. This raises the possibility that the presentation of certain neoantigens are important for control of tumor growth. This small exploratory study will provide the justification for a larger study of neoantigens in HNSCC.

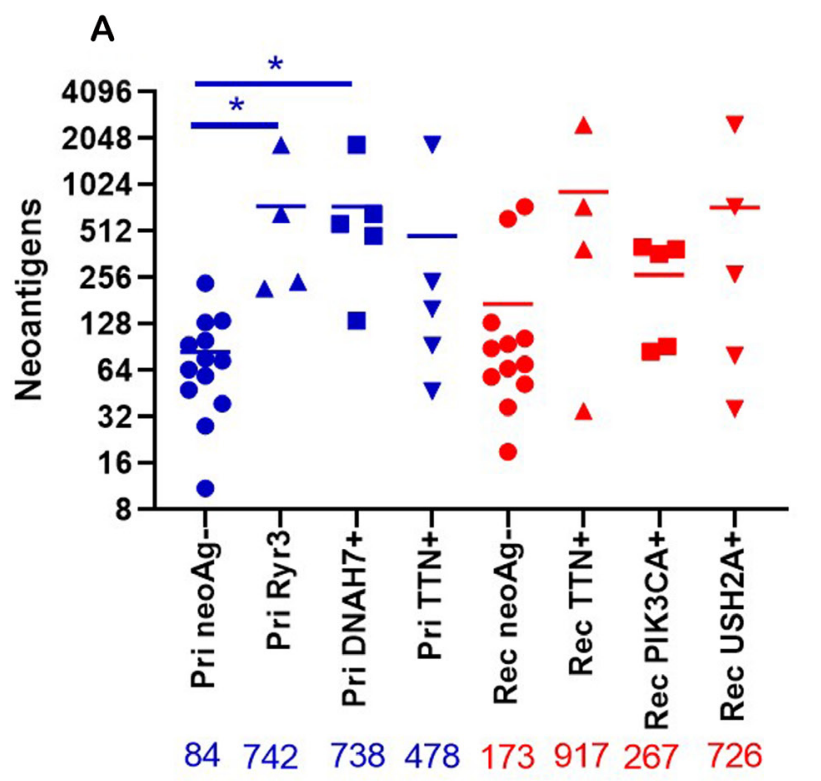

C

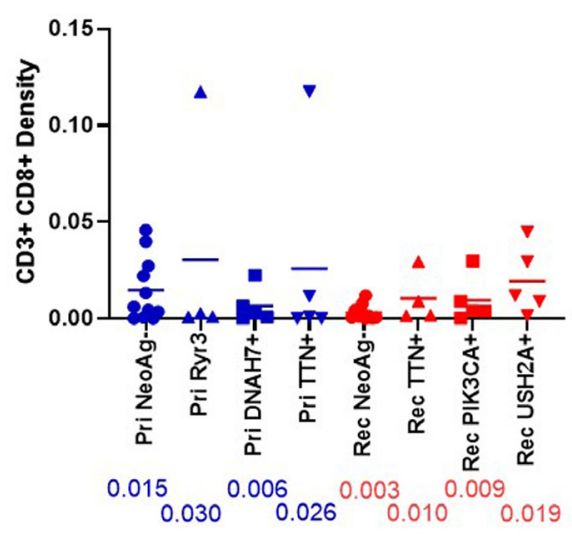

D

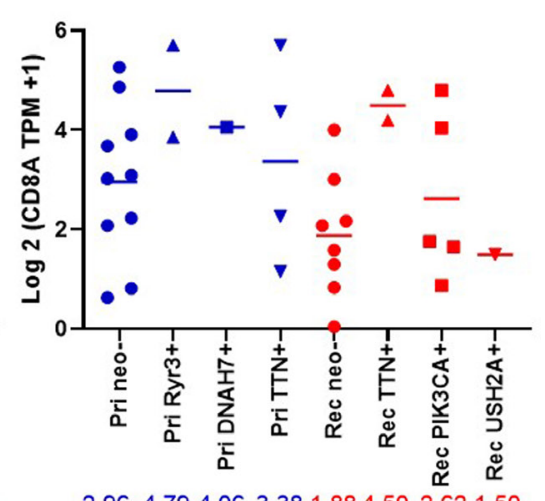

2.964 .794 .063 .381 .884 .502 .621 .50
B

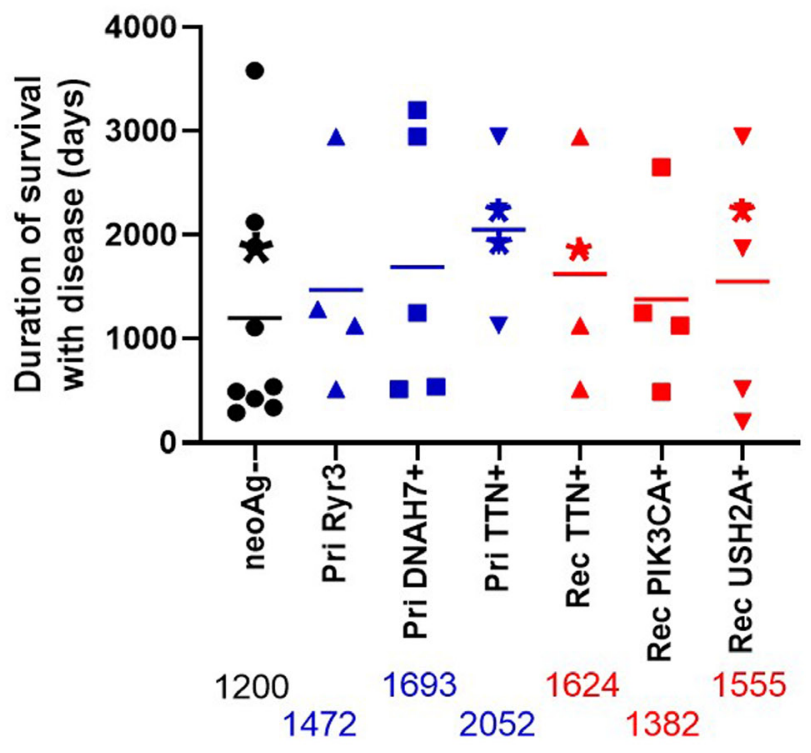

E

Figure 6: Properties of patients who have neoantigens in shared genes. (A) The total number of neoantigens was graphed for primary tumors with neoantigens in $\operatorname{Ryr} 3(n=4)$, DNAH7 $(n=5)$, TTN $(n=5)$, or no neoantigens (Pri neoAg-, $(n=13))$ or relapse tumors with neoantigens in TTN $(n=4)$, PIK3CA $(n=5)$, USH2A $(n=5)$, or no neoantigens $(\operatorname{Rel}$ neoAg-, $(n=12))$. The numbers under the X axis are the mean of neoantigens. "indicates $p<0.05$. (B) The duration of disease for patients with predicted neoantigens in the Primary tumor $(\operatorname{Ryr} 3(n=4)$, DNAH7 $(n=5)$, TTN $(n=4))$ and relapse tumor (TTN $(n=4)$, PIK3CA $(n=4)$, and USH2A $(n=5))$, or no predicted neoantigens in these genes (neoAg-, $(n=9))$. Patients with neoantigens in multiple genes are placed in all neoantigens. The asterisks indicate patients who were alive as of writing. (C) The density of CD3+ CD8+ cells in the tumor graphed by presence of neoantigens in shared genes. Primary RYR3 $(n=4)$, Primary DNAH7 $(n=5)$, Primary TTN $(n=5)$, Primary no neoantigens $(n=11)$, relapse TTN $(n=$ $4)$, relapse PIK3CA $(n=5)$, relapse USH2A $(n=5)$ relapse no neoantigens $(n=10))$. Numbers under the $\mathrm{X}$ axis are the mean of the density. (D) The $\log 2(\mathrm{TPM}+1)$ expression of CD8A was graphed by the presence of neoantigens in shared genes. Pri NeoAg- $(n=10)$, Pri Ryr3+ $(n=2)$, Pri DNAH7+ $(n=1)$, Pri TTN $+(n=4), \operatorname{Rel}$ neoAg- $(n=8), \operatorname{Rel~TTN}+(n=2), \operatorname{Rel~PIK} 3 \mathrm{CA}+(n=5), \operatorname{Rel} \mathrm{USH} 2 \mathrm{~A}+(n=1)$. The number under the $\mathrm{X}$ axis is the mean for each column. (E) The CTL activity was graphed by neoantigen status. CTL activity was calculated as described in Figure 4. Pri NeoAg- $(n=10)$, Pri Ryr3+ $(n=2)$, Pri DNAH7+ $(n=1)$, Pri TTN $+(n=3), \operatorname{Rel~neoAg-~}(n=8), \operatorname{Rel~TTN}+(n$ $=2)$, Rel PIK3CA+ $(n=5)$, Rel USH2A+ $(n=1)$. The number under the $\mathrm{X}$ axis is the mean for each column. 


\section{MATERIALS AND METHODS}

\section{Patient identification}

The HNSCC tumor bank at Washington University was queried for patients that had consented for genomic analysis IRB\#201102323. To be included in this study, tumor material had to be available from germline (white blood cells), primary tumors and first recurrence/metastases.

\section{Sequenced data set and filtering}

Of the 23 cases, a total of 69 samples (23 blood samples (for germline), 23 primary tumors, and 23 recurrent/metastatic tumors) had DNA and total RNA independently extracted, whole exome sequencing (WES), and RNA-Seq (performed using NovaSeq 6000 sequencing system). Of the raw data, the WES data included 23 blood normal samples, 23 primary tumors, and 23 recurrent/metastatic tumor samples. RNA-Seq raw data was available for 16 primary tumors and 15 recurrent/metastatic tumors. After that, adapter and lowquality sequences were trimmed from raw $2 \times 150 \mathrm{bp}$ paired-end reads using Trim Galore (v0.5.0) (https://www. bioinformatics.babraham.ac.uk/projects/trim galore). The resulting WES reads were then filtered for the duplicated reads and converted to bam format for use in downstream analysis. For the RNA-Seq, we used trimmed reads as the input to downstream analysis.

\section{Somatic variant calling}

Somatic mutations were determined using an in-house pipeline (https://github.com/ding-lab/ somaticwrapper) named as SomaticWrapper, which uses several somatic variant calling tools including Strelka (v2.9.2) [35], Mutect (v1.1.7) [36], VarScan (v2.3.8) [37] and Pindel (v0.2.5) [38]. To generate high confidence mutation callings, we used the mutations that supported at least 2 callers, cutoffs of at least 14 total reads in the tumor and at least 8 in the normal. The mutation list was further filtered by removing variant alleles observed in fewer than 4 reads, present at a variant allele frequency (VAF) less than 0.05 in tumor or higher than 0.01 VAF in the normal. For the candidate somatic mutations, we further filtered low quality mutations by bam-readcount (-q 10 -b 20) (https://github.com/genome/bam-readcount).

\section{Bulk RNA-seq methods}

Transcript quantification was performed using kallisto (v0.44.0) [26], against the GENCODE transcript reference (release 29, GRCh38). Subsequent analysis was performed using $\mathrm{R}$ (v3.6.0) and R package 'tximport' (v1.12.0) [39] was used to import and aggregate transcript level data to the gene-level. From the transcripts per million (TPMs), gene expression was calculated by log 2 (TPM +1). Significance was determined using Prism Graphpad (V8.4.3) using a paired two-tailed $t$ test with values determined to be significant when $p$-value $<0.05$.

\section{Neoantigen prediction}

HLA class I genotype was predicted from the WES data using OptiType (v1.2.1) [27]. Combined with HLA genotypes, non-synonymous mutations, and gene expression profile, MHC class I specific binding neoantigens were predicted using MuPeXI (v1.2.0) [28]. The binding affinity of MHC class I with candidate peptides were evaluated with netMHCpan-4.0 [40]. Candidate neoantigens were identified as those with a predicted mutant peptide binding affinity of $<500 \mathrm{nM}$ for peptides of length 8-11 amino acids. After that, the low gene expression $(\mathrm{TPM}<0.5)$ neoantigens were filtered, if the sample has RNA-Seq data. In addition, the inner-duplicated short peptides and the peptides with the same MHCaffinity values between normal and the tumor columns were removed from each sample.

\section{Quantitative multiplex immunofluorescence}

Six-marker multiplex immunofluorescence on 21 formalin-fixed paraffin embedded primary and recurrent/ metastatic tumors was performed using the PerkinElmer/ Akoya (Marlborough, MA) Opal reagents for multiplex immunofluorescence with the following primary antibodies CD3 (clone LN10, Leica \#NCL-L-CD3-565), HLA-DR (clone LN-3, Abcam \#ab166777), CD8 (clone 4B11, Leica \#PA0183), FoxP3 (clone 236A-37, Abcam \#ab20034), panCK (clone PCK-26, Abcam \#ab6401), and PD-L1 (clone SP142, Abcam \#ab228462), followed by image acquisition on the PerkinElmer/Akoya Vectra 3 automated multispectral microscope and data processing and analysis using the PerkinElmer/Akoya inForm analysis software. The density of $\mathrm{CD} 3+, \mathrm{CD} 3+\mathrm{HLA}-\mathrm{DR}+, \mathrm{CD} 3+\mathrm{CD} 8+\mathrm{CD} 3+\mathrm{FOXP} 3+$, and Tumor+ PD-L1+ cells inside the primary and recurrent/ metastatic tumors was determined from the software and was averaged for the primary and recurrent tumors. Significance was determined using Prism Graphpad using a Wilcoxon matched-pairs signed rank test with values determined to be significant when $p$-value $<0.05$.

\section{Statistics}

All other comparisons between more than two groups was done using Kruskal-Wallis test followed by Dunn's multiple comparison's test. Differences were determined to be significant when $p$-value $<0.05$.

\section{Author contributions}

BVT, LD, MI, YS, DA, and JL contributed to the study concept and design. CS, HS, JP, YS, MI, LD, and BVT 
contributed to the acquisition, analysis, and interpretation of data. CS, HS, and BVT drafted the manuscript. All authors read, revised and approved the final manuscript.

\section{ACKNOWLEDGMENTS}

We thank the Human Immune Monitoring Core (RRID:SCR_016740) at Columbia University Irving Medical Center for technical advice and support on the Vectra quantitative multiplex tissue imaging and analysis platform. We would also like to thank Dr. Lorne Michelle for his contributions to initiate this project.

\section{CONFLICTS OF INTEREST}

Charles Schutt: No disclosures, Hua Sun: No disclosures, Jaya Sarin: No disclosures, Dr. Adkins: Consulting or scientific advisory board support from Pfizer, Merck, Eli Lilly, Celgene (now BMS), Cue Biopharma. Institutional research support from Pfizer Eli Lilly, Merck, Celgene/BMS, Novartis, AstraZeneca, Atara Bio, Blueprint Medicine, Celldex, Enzychem, Kura, Exelixis, Innate, Sensei, and Matrix Biomed. Yvonne Saenger: Research funding from Amgen and Regeneron. Equity on a biomarker startup, Wasaba. Jessica Ley: No disclosures. Matthew Ingham: Consulting or Advisory role: Daiichi Sanky; Research Funding: Mirati Therapeutics, Apexigen, PTC Therapeutics; Travel, Accommodations, Expenses: Genetech, Mirati Therapeutics. Li Ding: No disclosures. Brian Van Tine: Grants from Merck, grants and personal fees from Pfizer, grants from Tracon, grants, personal fees and other from GSK, personal fees from Polaris, personal fees from Lilly, personal fees from Caris Life Sciences, personal fees from Novartis, personal fees from CytRX, personal fees from Plexxikon, personal fees from Epizyme, personal fees from Daiihi Sankyo, personal fees from Adaptimmune, personal fees from Immune Design, personal fees from Bayer, personal fees from Cytokinetics, personal fees from Deciphera. In addition, Dr. Van Tine has a patent on the use of ME1 as biomarker and ALEXT3102 issued.

\section{FUNDING}

Supported in part by a research grant from Investigator-Initiated Studies Program of Merck Sharp \& Dohme Corp. The opinions expressed in this paper are those of the authors and do not necessarily represent those of Merck Sharp \& Dohme Corp.

\section{Editorial note}

This paper has been accepted based in part on peerreview conducted by another journal and the authors' response and revisions as well as expedited peer-review in Oncotarget.

\section{REFERENCES}

1. Marur S, Forastiere AA. Head and neck cancer: changing epidemiology, diagnosis, and treatment. Mayo Clin Proc. 2008; 83:489-501. https://doi.org/10.4065/83.4.489.

2. Mehanna H, Paleri V, West CM, Nutting C. Head and neck cancer--Part 1: Epidemiology, presentation, and prevention. BMJ. 2010; 341:c4684. https://doi.org/10.1136/bmj.c4684. [PubMed]

3. Vermorken JB, Specenier P. Optimal treatment for recurrent/ metastatic head and neck cancer. Ann Oncol. 2010; 21:vii252-61. https://doi.org/10.1093/annonc/mdq453. [PubMed]

4. Argiris A, Karamouzis MV, Raben D, Ferris RL. Head and neck cancer. Lancet. 2008; 371:1695-709. https://doi. org/10.1016/s0140-6736(08)60728-x. [PubMed]

5. Denis F, Garaud P, Bardet E, Alfonsi M, Sire C, Germain $\mathrm{T}$, Bergerot $\mathrm{P}$, Rhein B, Tortochaux J, Calais G. Final results of the 94-01 French Head and Neck Oncology and Radiotherapy Group randomized trial comparing radiotherapy alone with concomitant radiochemotherapy in advanced-stage oropharynx carcinoma. J Clin Oncol. 2004; 22:69-76. https://doi.org/10.1200/jco.2004.08.021. [PubMed]

6. Lala M, Chirovsky D, Cheng JD, Mayawala K. Clinical outcomes with therapies for previously treated recurrent/ metastatic head-and-neck squamous cell carcinoma (R/M HNSCC): A systematic literature review. Oral Oncol. 2018; 84:108-20. https://doi.org/10.1016/j. oraloncology.2018.07.005. [PubMed]

7. Ferris RL, Blumenschein G, Fayette J, Guigay J, Colevas AD, Licitra L, Harrington K, Kasper S, Vokes EE, Even C, Worden F, Saba NF, Iglesias Docampo LC, et al. Nivolumab for Recurrent Squamous-Cell Carcinoma of the Head and Neck. N Engl J Med. 2016; 375:1856-67. https://doi. org/10.1056/NEJMoa1602252. [PubMed]

8. Ferris RL, Blumenschein G, Fayette J, Guigay J, Colevas AD, Licitra L, Harrington KJ, Kasper S, Vokes EE, Even C, Worden F, Saba NF, Docampo LCI, et al. Nivolumab vs investigator's choice in recurrent or metastatic squamous cell carcinoma of the head and neck: 2-year long-term survival update of CheckMate 141 with analyses by tumor PD-L1 expression. Oral Oncol. 2018; 81:45-51. https://doi. org/10.1016/j.oraloncology.2018.04.008. [PubMed]

9. Cohen EEW, Soulières D, Le Tourneau C, Dinis J, Licitra L, Ahn MJ, Soria A, Machiels JP, Mach N, Mehra R, Burtness B, Zhang P, Cheng J, et al. Pembrolizumab versus methotrexate, docetaxel, or cetuximab for recurrent or metastatic headand-neck squamous cell carcinoma (KEYNOTE-040): a randomised, open-label, phase 3 study. Lancet. 2019; 393:156-67. https://doi.org/10.1016/s0140-6736(18)31999-8. [PubMed]

10. Zandberg DP, Algazi AP, Jimeno A, Good JS, Fayette J, Bouganim N, Ready NE, Clement PM, Even C, Jang RW, Wong S, Keilholz U, Gilbert J, et al. Durvalumab 
for recurrent or metastatic head and neck squamous cell carcinoma: Results from a single-arm, phase II study in patients with $\geq 25 \%$ tumour cell PD-L1 expression who have progressed on platinum-based chemotherapy. Eur J Cancer. 2019; 107:142-52. https://doi.org/10.1016/j. ejca.2018.11.015. [PubMed]

11. Greenwald RJ, Freeman GJ, Sharpe AH. The B7 family revisited. Annu Rev Immunol. 2005; 23:515-48. https:// doi.org/10.1146/annurev.immunol.23.021704.115611. [PubMed]

12. Shibuya TY, Nugyen N, McLaren CE, Li KT, Wei WZ, Kim S, Yoo GH, Rogowski A, Ensley J, Sakr W. Clinical significance of poor $\mathrm{CD} 3$ response in head and neck cancer. Clin Cancer Res. 2002; 8:745-51. [PubMed]

13. Badoual C, Hans S, Rodriguez J, Peyrard S, Klein C, Agueznay NH, Mosseri V, Laccourreye O, Bruneval P, Fridman WH, Brasnu DF, Tartour E. Prognostic value of tumor-infiltrating CD4+ T-cell subpopulations in head and neck cancers. Clin Cancer Res. 2006; 12:465-72. https:// doi.org/10.1158/1078-0432.CCR-05-1886. [PubMed]

14. Karpathiou G, Casteillo F, Giroult JB, Forest F, Fournel P, Monaya A, Froudarakis M, Dumollard JM, Prades JM, Peoc'h M. Prognostic impact of immune microenvironment in laryngeal and pharyngeal squamous cell carcinoma: Immune cell subtypes, immuno-suppressive pathways and clinicopathologic characteristics. Oncotarget. 2017; 8:19310-22. https://doi.org/10.18632/oncotarget.14242. [PubMed]

15. Desrichard A, Kuo F, Chowell D, Lee KW, Riaz N, Wong RJ, Chan TA, Morris LGT. Tobacco Smoking-Associated Alterations in the Immune Microenvironment of Squamous Cell Carcinomas. J Natl Cancer Inst. 2018; 110:1386-92. https://doi.org/10.1093/jnci/djy060. [PubMed]

16. Jin Y, Qin X. Profiles of immune cell infiltration and their clinical significance in head and neck squamous cell carcinoma. Int Immunopharmacol. 2020; 82:106364. https://doi.org/10.1016/j.intimp.2020.106364.

17. de Ruiter EJ, Ooft ML, Devriese LA, Willems SM. The prognostic role of tumor infiltrating T-lymphocytes in squamous cell carcinoma of the head and neck: A systematic review and meta-analysis. Oncoimmunology. 2017; 6:e1356148. https://doi.org/10.1080/216240 2X.2017.1356148. [PubMed]

18. Chen DS, Mellman I. Oncology meets immunology: the cancer-immunity cycle. Immunity. 2013; 39:1-10. https:// doi.org/10.1016/j.immuni.2013.07.012. [PubMed]

19. Mo X, Zhang H, Preston S, Martin K, Zhou B, Vadalia N, Gamero AM, Soboloff J, Tempera I, Zaidi MR. Interferon- $\gamma$ Signaling in Melanocytes and Melanoma Cells Regulates Expression of CTLA-4. Cancer Res. 2018; 78:436-50. https://doi.org/10.1158/0008-5472.CAN-17-1615. [PubMed]

20. Garcia-Diaz A, Shin DS, Moreno BH, Saco J, EscuinOrdinas H, Rodriguez GA, Zaretsky JM, Sun L, Hugo W, Wang X, Parisi G, Saus CP, Torrejon DY, et al. Interferon
Receptor Signaling Pathways Regulating PD-L1 and PDL2 Expression. Cell Rep. 2017; 19:1189-201. https://doi. org/10.1016/j.celrep.2017.04.031. [PubMed]

21. Ginos MA, Page GP, Michalowicz BS, Patel KJ, Volker SE, Pambuccian SE, Ondrey FG, Adams GL, Gaffney PM. Identification of a gene expression signature associated with recurrent disease in squamous cell carcinoma of the head and neck. Cancer Res. 2004; 64:55-63. https://doi. org/10.1158/0008-5472.can-03-2144. [PubMed]

22. Goesswein D, Habtemichael N, Gerhold-Ay A, Mazur J, Wünsch D, Knauer SK, Künzel J, Matthias C, Strieth S, Stauber RH. Expressional analysis of disease-relevant signalling-pathways in primary tumours and metastasis of head and neck cancers. Sci Rep. 2018; 8:7326. https://doi. org/10.1038/s41598-018-25512-7. [PubMed]

23. Karpathiou G, Stachowitz ML, Dumollard JM, Gavid M, Froudarakis M, Prades JM, Peoc'h M. Gene Expression Comparison Between the Primary Tumor and its Lymph Node Metastasis in Head and Neck Squamous Cell Carcinoma: A Pilot Study. Cancer Genomics Proteomics. 2019; 16:155-61. https://doi.org/10.21873/cgp.20121. [PubMed]

24. Puram SV, Tirosh I, Parikh AS, Patel AP, Yizhak K, Gillespie S, Rodman C, Luo CL, Mroz EA, Emerick KS, Deschler DG, Varvares MA, Mylvaganam R, et al. Single-Cell Transcriptomic Analysis of Primary and Metastatic Tumor Ecosystems in Head and Neck Cancer. Cell. 2017; 171:1611-24.e24. https://doi.org/10.1016/j. cell.2017.10.044. [PubMed]

25. The Cancer Genome Atlas Network. Comprehensive genomic characterization of head and neck squamous cell carcinomas. Nature. 2015; 517:576-82. https://doi. org/10.1038/nature14129. [PubMed]

26. Bray NL, Pimentel H, Melsted P, Pachter L. Near-optimal probabilistic RNA-seq quantification. Nat Biotechnol. 2016; 34:525-7. https://doi.org/10.1038/nbt.3519. [PubMed]

27. Szolek A, Schubert B, Mohr C, Sturm M, Feldhahn M, Kohlbacher O. OptiType: precision HLA typing from next-generation sequencing data. Bioinformatics. 2014; 30:3310-6. https://doi.org/10.1093/bioinformatics/btu548. [PubMed]

28. Bjerregaard AM, Nielsen M, Hadrup SR, Szallasi Z, Eklund AC. MuPeXI: prediction of neo-epitopes from tumor sequencing data. Cancer Immunol Immunother. 2017; 66:1123-30. https://doi.org/10.1007/s00262-017-2001-3. [PubMed]

29. Yeh MH, Tzeng YJ, Fu TY, You JJ, Chang HT, Ger LP, Tsai KW. Extracellular Matrix-receptor Interaction Signaling Genes Associated with Inferior Breast Cancer Survival. Anticancer Res. 2018; 38:4593-605. https://doi. org/10.21873/anticanres.12764. [PubMed]

30. Chen X, Pei Z, Peng H, Zheng Z. Exploring the molecular mechanism associated with breast cancer bone metastasis using bioinformatic analysis and microarray genetic interaction network. Medicine. 2018; 97:e12032. https:// doi.org/10.1097/MD.0000000000012032. [PubMed] 
31. Bailey MH, Tokheim C, Porta-Pardo E, Sengupta S, Bertrand D, Weerasinghe A, Colaprico A, Wendl MC, Kim J, Reardon B, Ng PK, Jeong KJ, Cao S, et al. Comprehensive Characterization of Cancer Driver Genes and Mutations. Cell. 2018; 173:371-85.e18. https://doi. org/10.1016/j.cell.2018.02.060. [PubMed]

32. Rooney MS, Shukla SA, Wu CJ, Getz G, Hacohen N. Molecular and genetic properties of tumors associated with local immune cytolytic activity. Cell. 2015; 160:48-61. https://doi.org/10.1016/j.cell.2014.12.033. [PubMed]

33. Starska K, Głowacka E, Kulig A, Lewy-Trenda I, Bryś M, Lewkowicz P. The role of tumor cells in the modification of $\mathrm{T}$ lymphocytes activity--the expression of the early CD69+, CD71+ and the late CD25+, CD26+, HLA/DR+ activation markers on T CD4+ and CD8+ cells in squamous cell laryngeal carcinoma. Part I. Folia Histochem Cytobiol. 2011; 49:579-92. https://doi.org/10.5603/FHC.2011.0081. [PubMed]

34. Reddy M, Eirikis E, Davis C, Davis HM, Prabhakar U. Comparative analysis of lymphocyte activation marker expression and cytokine secretion profile in stimulated human peripheral blood mononuclear cell cultures: an in vitro model to monitor cellular immune function. J Immunol Methods. 2004; 293:127-42. https://doi.org/10.1016/j. jim.2004.07.006. [PubMed]

35. Kim S, Scheffler K, Halpern AL, Bekritsky MA, Noh E, Källberg M, Chen X, Kim Y, Beyter D, Krusche P, Saunders CT. Strelka2: fast and accurate calling of germline and somatic variants. Nat Methods. 2018; 15:591-4. https://doi. org/10.1038/s41592-018-0051-x. [PubMed]
36. Cibulskis K, Lawrence MS, Carter SL, Sivachenko A, Jaffe D, Sougnez C, Gabriel S, Meyerson M, Lander ES, Getz G. Sensitive detection of somatic point mutations in impure and heterogeneous cancer samples. Nat Biotechnol. 2013; 31:213-9. https://doi.org/10.1038/nbt.2514. [PubMed]

37. Koboldt DC, Zhang Q, Larson DE, Shen D, McLellan MD, Lin L, Miller CA, Mardis ER, Ding L, Wilson RK. VarScan 2: somatic mutation and copy number alteration discovery in cancer by exome sequencing. Genome Res. 2012; 22:568-76. https://doi.org/10.1101/gr.129684.111. [PubMed]

38. Ye K, Schulz MH, Long Q, Apweiler R, Ning Z. Pindel: a pattern growth approach to detect break points of large deletions and medium sized insertions from paired-end short reads. Bioinformatics. 2009; 25:2865-71. https://doi. org/10.1093/bioinformatics/btp394. [PubMed]

39. Soneson C, Love MI, Robinson MD. Differential analyses for RNA-seq: transcript-level estimates improve genelevel inferences. F1000Res. 2015; 4:1521. https://doi. org/10.12688/f1000research.7563.2. [PubMed]

40. Jurtz V, Paul S, Andreatta M, Marcatili P, Peters B, Nielsen M. NetMHCpan-4.0: Improved Peptide-MHC Class I Interaction Predictions Integrating Eluted Ligand and Peptide Binding Affinity Data. J Immunol. 2017; 199:33608. https://doi.org/10.4049/jimmunol.1700893. [PubMed] 